\title{
Color chart for thin SiC films grown on Si substrates
}

\author{
Li Wang ${ }^{1, a}$, Sima Dimitrijev ${ }^{1, b}$, Glenn Walker ${ }^{1, c,}$ Jisheng Han ${ }^{1, d}$, Alan Iacopi, ${ }^{1, e}$, \\ Philip Tanner ${ }^{1, \mathrm{f}}$, Leonie Hold ${ }^{1, \mathrm{~g}}$, Yu Zhao ${ }^{1, \mathrm{~h}}$, and Francesca Iacopi ${ }^{1, \mathrm{i}}$ \\ Queensland Micro- and Nanotechnology Centre, Griffith University, Nathan, Qld, 4111, Australia

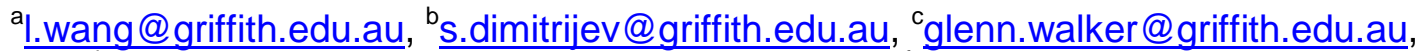 \\ di.han@griffith.edu.au, ${ }^{e}$ a.iacopi@griffith.edu.au, ${ }^{f}$ p.tanner@griffith.edu.au, \\ gl.hold@griffith.edu.au, ${ }^{\mathrm{h} y . z h a o @ g r i f f i t h . e d u . a u}$, if.iacopi@griffith.edu.au
}

Keywords: Silicon carbide; color chart; epitaxial growth; thin film; alternating supply epitaxy, Si substrate.

\begin{abstract}
In this paper, a color chart based on experimental data was defined for thin SiC films grown on Si substrates. For SiC films thinner than $500 \mathrm{~nm}$, the surface color was observed using an optical microscope with the incident light normally illuminated on the SiC surface. An image of the surface was then taken by a camera attached to the optical microscope and the surface color was defined using RGB code. For SiC films thicker than $500 \mathrm{~nm}$, the colors were defined by observing the films under daylight fluorescent lighting by naked eyes. It was found that the colors of the SiC films varied as the thickness increased.
\end{abstract}

\section{Introduction}

The potential of integrating SiC-based electronics with mature Si technology by heteroepitaxial growth of 3C-SiC films on Si substrates has been attracting increasing attention. In addition to that, the 3C-SiC/Si structure acts as an excellent cost-effective template for graphene preparation and $\mathrm{GaN}$ growth [1-3]. Thin $\mathrm{SiC}$ films grown on $\mathrm{Si}$ substrates are also desirable candidates for the fabrication of pressure sensors [4]. The required SiC layer thickness for these applications ranges from a few nanometers to a few micrometers. 3C-SiC films can be grown on Si substrates by concurrent supply epitaxy performed at around $1300{ }^{\circ} \mathrm{C}$ [5-6] and alternating supply epitaxy (ASE) conducted at around $1000{ }^{\circ} \mathrm{C}$ [7-10]. The ASE method has the advantage of reducing wafer bow due to the relatively lower growth temperature [10]. Although the growth rate is lower, the ASE method enables excellent thickness uniformity across large scale wafers (non-uniformity is less than $1 \%)[7,10]$.

Color charts for thin films have been developed for silicon dioxide $\left(\mathrm{SiO}_{2}\right)$ and silicon nitride $\left(\mathrm{Si}_{3} \mathrm{~N}_{4}\right)$ [11-12], because they are widely used in the fabrication of integrated electronic and optical devices. The color change is caused by variations in the reflectance [12], which depends on the wavelength of the incident light, the thickness and the optical properties of the thin film. Theoretical calculations of the colors for $\mathrm{SiO}_{2}$ and $\mathrm{Si}_{3} \mathrm{~N}_{4}$ films on $\mathrm{Si}$ substrates have also been performed [13]. Recently, the colors of graphene and graphene-oxide prepared on various dielectric layers were investigated by both theoretical calculation and experimental observation [14]. However, to date no theoretical or experimental data available for the colors of $\mathrm{SiC}$ films grown on $\mathrm{Si}$ substrates. With the increasing research interests in $\mathrm{SiC}$, it is helpful to define a color chart using experimental data for monocrystalline 3C-SiC films grown on Si substrates. This would enable experienced technicians and researchers to estimate the thickness of a SiC film simply by observing its color.

\section{Experimental details}

Monocrystalline 3C-SiC films were grown on on-axis $150 \mathrm{~mm} \mathrm{Si(100)}$ and $\mathrm{Si}(111)$ substrates in a hot-wall low-pressure chemical vapor deposition (LPCVD) reactor. The growth was performed at $1000{ }^{\circ} \mathrm{C}$ with $\mathrm{SiH}_{4}$ (99.9994\%) and $\mathrm{C}_{3} \mathrm{H}_{6}$ (99.999\%) being used as precursors. The idle temperature of the reactor was set at $600{ }^{\circ} \mathrm{C}$. Si surface cleaning was performed by supplying 1.5 SCCM (standard cubic centimeter per minute)) $\mathrm{SiH}_{4}$ at $1000{ }^{\circ} \mathrm{C}$, followed by carbonization performed 
using $\mathrm{C}_{3} \mathrm{H}_{6}$ gas. Then the epitaxial growth of $3 \mathrm{C}$-SiC was performed at $1000{ }^{\circ} \mathrm{C}$ cycle by cycle using the ASE method, each cycle consisted of the following four steps: 1) A supply of $\mathrm{SiH}_{4}$ for 60 $\mathrm{s}$ with a flow rate in the range of 1.0 to 2.5 SCCM; 2) Pump out for $10 \mathrm{~s}$; 3) A supply of $\mathrm{C}_{3} \mathrm{H}_{6}(0.5$ to $10 \mathrm{SCCM}$ ) for $20 \mathrm{~s}$; 4) Pump out for $10 \mathrm{~s}$. The thicknesses of SiC films were measured by NANOMETRICS NanoSpec/AFT 210, assuming a refractive index of 2.65. The wavelength of the incident light ranged from 480 to $800 \mathrm{~nm}$. The thicknesses of these SiC films were then verified by ellipsometry measurement (Rudolph AutoEL IV Ellipsometer, wavelength: $632.8 \mathrm{~nm}$, Phi $=70^{\circ}$ ). The color of the SiC film was observed under bright field (magnification of 100 times) using an optical microscope (OLYMPUS MX50, the light source color temperature was set at 3200 3400 K) with the incident light normally illuminated on the SiC surface. An image of the surface was then recorded by a camera (Cannon powershot A640, using auto white balance, the expected temperature range is from 3000 to $7000 \mathrm{~K}$ ) attached to the optical microscope. The colors of these SiC films were defined using standard RGB parameters (they can be displayed on a computer monitor), based on the color definition from online information [15].

\section{Results and discussion}

The thickness of SiC films studied in this paper ranged from $7 \mathrm{~nm}$ to $1185 \mathrm{~nm}$, and the corresponding colors are summarized and listed in Table 1 and 2. For SiC films thicker than 500 $\mathrm{nm}$, the optical microscope and/or the camera were insensitive to the color changes, the colors shown in the images taken by the camera were either green-purplish or dim gray, which did not vary correspondingly to the change in SiC thickness. Therefore, for SiC films with thicknesses beyond $500 \mathrm{~nm}$, the color was described by observing these films by naked eyes under daylight fluorescent lighting. It was found that the colors of these films varied with the increase in thickness and the results were shown in Table 1. Only limited results are given for thicker SiC film because the emphasis of this paper is on SiC films with a thickness less than $500 \mathrm{~nm}$ (as shown in table 2). An image of the virgin Si substrate taken by the camera is also listed in table 2 for reference.

The experimental results shown in table 2 indicated that the colors of the $\mathrm{SiC}$ films grown on $\mathrm{Si}$ substrates varied as the thickness increased; however, it is not practical/scientific to define a thickness period for each color to repeat, because it is similar colors that occurred at different thicknesses, but usually not exactly the same colors. The color variation but not repetition with increasing thickness was theoretically demonstrated for silicon dioxide and silicon nitride films [13]. For a given refractive index of 2.65 for stoichiometric SiC materials, this color chart would also apply to poly $\mathrm{SiC}$ and amorphous $\mathrm{SiC}$.

Table 1. The color chart for SiC films thicker than $500 \mathrm{~nm}$, observed by naked eyes under daylight fluorescent lighting.

\begin{tabular}{lll}
\hline \hline $\begin{array}{l}\text { Thickness } \\
{[\mathrm{nm}]}\end{array}$ & Color Name & $\begin{array}{l}\text { RGB Code } \\
{[0-255]}\end{array}$ \\
\hline 508 & Purple to medium sea green & $160-32-240$ to $60-179-113$ \\
515 & Medium sea green & $60-179-113$ \\
540 & Pale violet red & $219-112-147$ \\
552 & Maroon & $176-48-96$ \\
615 & Pale green & $152-251-152$ \\
645 & Medium orchid & $186-85-211$ \\
700 & Thistle & $216-191-216$ \\
945 & Medium orchid & $186-85-211$ \\
958 & Medium orchid & $186-85-211$ \\
988 & Pale green & $152-251-152$ \\
996 & Pale green & $152-251-152$ \\
1040 & Medium orchid & $186-85-211$ \\
1185 & Pale violet red to dark olive green & $219-112-147$ to 85-107-47 \\
\hline \hline
\end{tabular}


Table 2. The color chart for SiC films thinner than $500 \mathrm{~nm}$ grown on Si substrate, observed under microscope by normal illumination light (magnification of 100 times).

\begin{tabular}{|c|c|c|c|c|c|c|c|}
\hline $\begin{array}{l}\text { Thickn } \\
\text { ess } \\
\text { [nm] }\end{array}$ & Image & Color Name & $\begin{array}{l}\text { RGB Code } \\
{[0-255]}\end{array}$ & $\begin{array}{l}\text { Thickn } \\
\text { ess } \\
\text { [nm] }\end{array}$ & Image & Color Name & $\begin{array}{l}\text { RGB Code } \\
{[0-255]}\end{array}$ \\
\hline $\begin{array}{l}\text { Bare } \\
\text { Si }\end{array}$ & & Dim gray & $105-105-105$ & 206 & & $\begin{array}{l}\text { Green } \\
\text { yellow }\end{array}$ & $173-255-47$ \\
\hline 15 & & Dim gray & 105-105-105 & 218 & & Gold & $255-215-0$ \\
\hline 40 & & $\begin{array}{l}\text { Dark } \\
\text { goldenrod }\end{array}$ & 184-134-11 & 230 & & Brown & $165-42-42$ \\
\hline 53 & & Blue violet & $138-43-226$ & 240 & & Violet & $238-130-238$ \\
\hline 63 & & Royal blue & $65-105-225$ & 253 & & Blue violet & $138-43-226$ \\
\hline 83 & & $\begin{array}{l}\text { Light steel } \\
\text { blue }\end{array}$ & $176-196-222$ & 264 & & $\begin{array}{l}\text { Medium } \\
\text { purple }\end{array}$ & $147-112-219$ \\
\hline 95 & & $\begin{array}{l}\text { Dark olive } \\
\text { green }\end{array}$ & $85-107-47$ & 268 & & $\begin{array}{l}\text { Light slate } \\
\text { blue }\end{array}$ & $132-112-255$ \\
\hline 110 & & Dark khaki & 189-183-107 & 278 & & $\begin{array}{l}\text { Medium } \\
\text { aquamarine }\end{array}$ & $102-205-170$ \\
\hline 120 & & $\begin{array}{l}\text { Dark } \\
\text { goldenrod }\end{array}$ & $184-134-11$ & 288 & & $\begin{array}{l}\text { Medium sea } \\
\text { green }\end{array}$ & 60-179-113 \\
\hline 127 & & Goldenrod & 218-165-32 & 298 & & Forest green & 34-139-34 \\
\hline 132 & & $\begin{array}{l}\text { Saddle } \\
\text { brown }\end{array}$ & 136-69-19 & 317 & & $\begin{array}{l}\text { Dark olive } \\
\text { green }\end{array}$ & $85-107-47$ \\
\hline 140 & & $\begin{array}{l}\text { Dark } \\
\text { salmon }\end{array}$ & 233-150-122 & 329 & & Olive drab & $107-142-35$ \\
\hline 147 & & $\begin{array}{l}\text { Medium } \\
\text { orchid }\end{array}$ & 186-85-211 & 335 & & Light coral & $240-128-128$ \\
\hline 155 & & Purple & $160-32-240$ & 345 & & Orchid & 218-112-214 \\
\hline 159 & & $\begin{array}{l}\text { Medium } \\
\text { slate blue }\end{array}$ & $123-104-238$ & 357 & & Light pink & 255-182-193 \\
\hline 163 & & Slate blue & 106-90-205 & 387 & & $\begin{array}{l}\text { Medium sea } \\
\text { green }\end{array}$ & $60-179-113$ \\
\hline 174 & & Dodger blue & $30-144-255$ & 399 & & $\begin{array}{l}\text { Medium } \\
\text { spring green }\end{array}$ & $0-250-154$ \\
\hline 188 & & $\begin{array}{l}\text { Medium } \\
\text { aquamarine }\end{array}$ & $102-205-170$ & 465 & & Rosy brown & 188-143-143 \\
\hline 196 & & $\begin{array}{l}\text { Yellow } \\
\text { green }\end{array}$ & $154-205-50$ & 487 & & Plum & $221-160-221$ \\
\hline
\end{tabular}

\section{Summary}

In this paper, a color chart was defined for monocrystalline SiC thin films grown on $\mathrm{Si}$ substrates. The specific color of the SiC film (thinner than $500 \mathrm{~nm}$ ) was observed under bright field using an optical microscope and defined using the standard RGB code. For SiC films thicker than $500 \mathrm{~nm}$, the colors shown in the images taken by the camera did not vary correspondingly to the change in SiC thickness, therefore, the colors were defined by observing the films by naked eyes 
under daylight fluorescent lighting. It was found that the colors of the $\mathrm{SiC}$ films varied as the thickness increased. The color chart would enable experienced technicians and researchers to estimate the thickness of a SiC film simply by observing its color.

For a given refractive index of 2.65 for stoichiometric $\mathrm{SiC}$ materials, this color chart would also apply to poly $\mathrm{SiC}$ and amorphous $\mathrm{SiC}$.

\section{Acknowledgements}

The SiC deposition was performed at Queensland Microtechnology Facility, Griffith University, Australia. This work was performed in part at the Queensland node of the Australian National Fabrication Facility. A company established under the National Collaborative Research Infrastructure Strategy to provide nano and microfabrication facilities for Australia's researchers.

\section{References}

[1] V.Y. Aristov, G. Urbanik, K. Kummer, D.V. Vyalikh, O.V. Molodtsova, A.B. Preobrajenski, et. al., Nano Lett. 10, 992 (2010).

[2] A. Ouerghi, A. Kahouli, D. Lucot, M. Portail, L. Travers, J. Geirak, et. al., Appl. Phys. Lett. 96, 191910 (2010).

[3] D. Wang, Y. Hiroyama, M. Tamura, M. Ichikawa, and S. Yoshida, Appl. Phys. Lett. 77, 1846 (2000).

[4] Darrin J. Young, Jiangang Du, Christian A. Zorman, and Wen H. Ko, IEEE Sensors J. 4, 464 (2004).

[5] M. Portail, M. Zielinski., T. Chasssagne, S. Roy, M. Nemoz, J. Appl. Phys. 105, 083505 (2009).

[6] A. Severino, C. Bongiorno, N. Piluso, M. Italia, M. Camarda, M. Mauceri, G. Condorelli, M.A. Di Stefano, B. Cafra, A. La Magna, F. La Via, Thin Solid Films 518, s165 (2010).

[7] H. Nagasawa, K. Yagi, Phys. Status Solidi B 202, 335 (1997).

[8] T. Fuyuki, T. Yoshinobu, H. Matsunami, Thin Solid Films 225, 225 (1993).

[9] L. Wang, S. Dimitrijev, J. Han, P. Tanner, A. Iacopi, and L. Hold, J. Cryst. Growth 329, 67 (2011).

[10] L. Wang, S. Dimitrijev, J. Han, A. Iacopi, L. Hold, P. Tanner, and H.B. Harrison, Thin Solid Films 519, 6443 (2011).

[11] W.A. Pliskin and E.E. Conrad, IBM Journal of Research and Development, 8, 43 (1964).

[12] T. Huen, Appl. Opt.18, 1927 (1979).

[13] J. Henrie, S. Kellis, S.M. Schultz, and A. Hawkins, Opt. Express 12, 1464 (2004).

[14] I. Jung, J. Rhyee, J. Y. Son, R. S. Ruoff and K. Rhee, Nanotechnology 23, 025708 (2012).

[15] Information on http://www.tayloredmktg.com/rgb/. 